\title{
Comparación de las eficiencias de recuperación de lípidos de las microalgas Chlorella y Scenedesmus obtenidas con diferentes disolventes
}

\author{
María J. Pérez', Jenny Quishpi ${ }^{1}$, Guillermina Pauta ${ }^{1}$, Fabián León ${ }^{2}$, Juan F. Cisneros ${ }^{2}$ (D), Verónica Pinos ${ }^{2,3}$ (D), \\ Andrés Alvarado ${ }^{1,3}$ iD \\ 1 Facultad de Ingeniería, Universidad de Cuenca, Av. 12 de Abril y Ciudadela Universitaria, Cuenca, Ecuador. \\ 2 Facultad de Ciencias Químicas, Universidad de Cuenca, Av. 12 de Abril y Ciudadela Universitaria, Cuenca, Ecuador. \\ 3 Departamento de Recursos Hídricos y Ciencias Ambientales, Universidad de Cuenca, Campus Balzay, Cuenca, Ecuador. \\ Autor para correspondencia: andres.alvarado@ucuenca.edu.ec; juan.cisneros@ucuenca.edu.ec \\ Fecha de recepción: 18 de octubre de 2018-Fecha de aceptación: 11 de diciembre de 2018
}

\section{RESUMEN}

Las microalgas son capaces de producir lípidos que pueden ser usados para obtener biocombustibles de tercera generación, los cuales buscan reemplazar a los combustibles fósiles. Los objetivos de este estudio fueron: determinar la composición de lípidos de las microalgas Chlorella y Scenedesmus usando el método gravimétrico; determinar la eficiencia de diferentes solventes para la extracción de lípidos con el método Soxhlet; y comparar las productividades de recuperación de lípidos de las microalgas Chlorella obtenidas con pretratamientos térmico y físico. Los resultados obtenidos muestran que se recuperó la mayor cantidad de lípidos, un $20.37 \%$ por muestra seca, en la microalga Chlorella usando una la mezcla de disolventes cloroformo: metanol en proporción 1:2. El aumento de la cantidad de lípidos, generado con el uso de pretratamientos, no justifica su uso, por lo que se recomienda que no se aplique un pretratamiento. Los resultados permiten establecer una línea base en el aprovechamiento de microalgas cultivables en la serranía ecuatoriana para la obtención de lípidos para biocombustibles.

Palabras clave: lípidos, extracción, microalgas, biodiesel, disolventes.

\begin{abstract}
The lipids of microalgae are the source for obtaining third-generation biofuels so that fossil fuels can be replaced. The objectives of this study were to determine the composition of the lipids of Chlorella and Scenedesmus microalgae using the gravimetric method; Determine the efficiency of different solvents for the extraction of lipids with the Soxhlet method and compare the lipid recovery productivities of Chlorella microalgae with thermal and physical pretreatments. The highest amount of lipids, $20.37 \%$ per dry sample, the microalga, the chlorella, the solvent mixture, the chloroform:methanol in a 1:2 ratio. The increase in the amount of lipids generated with the use of pretreatments no justifies its use for which it is recommended that no pretreatment be applied. The results allow to establish a baseline in the use of microalgae cultivable in the Ecuadorian mountain to obtain lipids for biofuels.
\end{abstract}

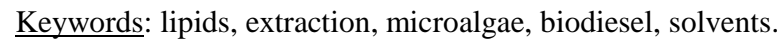

\section{INTRODUCCIÓN}

El rápido incremento de la concentración de dióxido de carbono $\left(\mathrm{CO}_{2}\right)$ en la atmósfera, combinado con el desgaste de las reservas de combustibles fósiles, ha conducido a un mayor interés comercial en las fuentes de energía renovables (Halim, Danquah, \& Webley, 2012; AriasPeñaranda, Martínez-Roldán, \& Cañizares-Villanueva, 2013). Las microalgas tienen una capacidad de crecer rápidamente, sintetizar y acumular grandes cantidades de lípidos (Grobbelaar, 2004; Chen, Zhao, \& Qi, 2015). Una industria de producción de aceite de algas, exitosa y económicamente viable, dependerá de la selección de cepas apropiadas de microalgas y de la selección del mejor método de extracción de lípidos (Araujo et al., 2013). Una alternativa altamente fiable es el biodiesel producido mediante transesterificación de lípidos extraídos de microalgas, con una huella de carbono neutral, siendo una tecnología que no compite con cultivos agrícolas tradicionales (Medipally, Yusoff, Banerjee, \& Shariff, 2015). Sin embargo, existe una alta variabilidad entre las especies de microalgas referente a su capacidad para sintetizar sustancias oleaginosas que depende, en gran medida, de las características ambientales y concentración de nutrientes del medio que las sustenta (Abou-Shanab, Hwang, Cho, Min, \& Jeon, 2011; Amaro, Guedes, \& Malcata, 2011).

La biomasa de microalgas contiene tres componentes principales: proteínas, carbohidratos y lípidos (aceite) (Dragone, Fernandes, Vincete, \& Teixeira, 2010). Los lípidos pueden ser definidos como cualquier molécula biológica que es soluble en un solvente orgánico. La mayoría de los lípidos contienen ácidos grasos y, generalmente, pueden clasificarse en dos categorías en base a su polaridad: (1) lípidos neutros, que comprenden acilgliceroles y ácidos grasos libres (FFA); y, (2) lípidos polares, que pueden subclasificarse en fosfolípidos (PL) y glicolípidos (GL) (Halim et al., 2012). 
El proceso de producción de biodiesel a partir de microalgas está conformado en términos generales por las etapas indicadas en la Figura 1 (Garibay, Vázquez-Duhalt, Sánchez, M.d.P., Serrano, \& Martínez, 2009). Para el cultivo de biomasa, el agua, los nutrientes, el $\mathrm{CO}_{2}$ y la luz, son proporcionados a los sistemas de cultivos (abiertos, cerrados o híbridos). $\mathrm{El} \mathrm{CO}_{2}$ suministrado puede provenir del aire del ambiente, o bien, los sistemas de cultivo pueden ser acoplados a flujos ricos con este gas procedente de emisiones industriales, tales como las de las plantas generadoras de energía eléctrica. En la Cosecha, la biomasa producida es separada del agua (Cai, Park, \& Li, 2013). El Secado, y la Extracción de lípidos, seguido por la Conversión de lípidos extraídos a biodiesel y glicerol mediante la Transerificación, y, finalmente, la purificación del biodiesel producido (Garibay et al., 2009; Taher, AlZuhair, Al-Marzouqi, Haik, \& Farid, 2014; Khan, Shin, \& Kim, 2018).

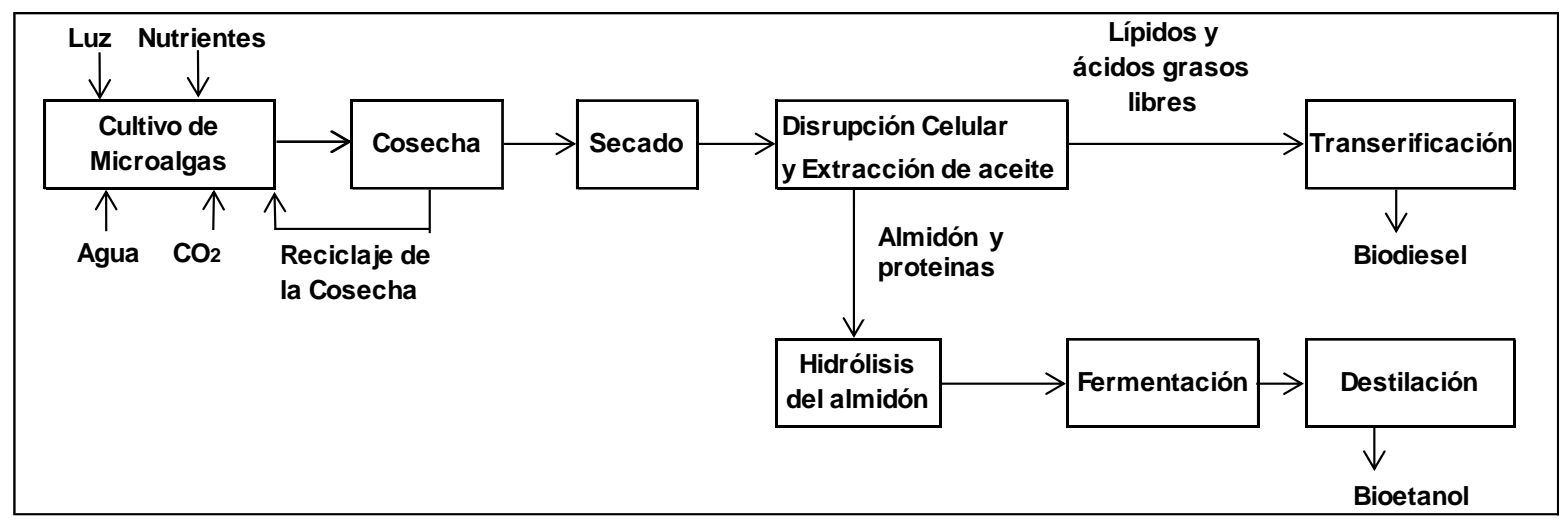

Figura 1. Proceso integrado de producción de biodiesel y bioetanol a partir de microalgas (Garibay et al., 2009).

Con el fin de producir biodiesel a partir de la biomasa celular algal, los lípidos deben ser extraídos de la célula y recolectarse (Lee, Lewis, \& Ashman, 2012). Esto requiere la interrupción o ruptura de la célula algal y se puede lograr usando una variedad de métodos como la rotura mecánica y química, la extracción con solvente, la extracción con fluidos supercríticos, y combinaciones o variaciones de estas técnicas (Sathish \& Sims, 2012). Varios métodos de extracción pueden ser utilizados para extraer el lípido a partir de biomasa seca de microalgas. Las técnicas más usadas son Folch, Bligh y Dyer, y Soxhlet (Taher et al., 2014). Existen varios estudios de la etapa de extracción del aceite de las microalgas para su posterior transformación a biodiesel debido a la importancia de esta etapa en la eficiencia y los costos globales del proceso (González, Viatcheslav, \& Guzmán, 2009). Técnicas de extracción con solvente son ampliamente usadas y eficaces para la extracción de lípidos a partir de microalgas (Brennan \& Owende, 2010). Esto es debido a la alta solubilidad de los lípidos en solventes no polares tales como cloroformo, hexano y éter de petróleo.

Existen diferentes protocolos de extracción estándar tal como la extracción Folch, Bligh y Dyer, y el Soxhlet o técnicas de Gold-Fisch. Aunque el uso de solventes para extraer lípidos de algas es bastante sencillo, hay inconvenientes cuando se aplica a las microalgas. Para tener resultados óptimos, la extracción requiere que el agua se elimine de la biomasa antes de la extracción de lípidos. Si la biomasa no se seca hasta un cierto punto, el agua tiende a interferir en el proceso de extracción, protegiendo los lípidos de la extracción con el solvente. Una gran cantidad de solventes se han utilizado como solventes de extracción en el método Soxhlet, el uso de un solvente no polar será selectivo al extraer lípidos no polares de las microalgas como los triglicéridos, los cuales son lípidos ideales para la producción de biodiesel (González et al., 2009).
Además de los desafíos de extracción, el contenido de lípidos de las células de microalgas es importante ya que varía por especie de alga (Milano et al., 2016). La efectividad promedio de la producción de biodiesel de microalgas depende de la productividad del lípido, que es un efecto combinado de la productividad de biomasa y el contenido de lípidos. El contenido de lípidos informado de microalgas está en el intervalo de 20-30\% (base seca) cuando las microalgas se cultivan en condiciones controladas, con suficientes nutrientes. Sin embargo, bajo condiciones de estrés, las microalgas pueden acumular mayor contenido de lípidos. La primera condición de estrés, aplicada a las microalgas verdes, es la deficiencia de nitrógeno, donde acumulaciones de más de 50\% (base seca) han sido reportadas. Esto se debe principalmente a la falta de nitrógeno necesario para la síntesis de proteínas. El exceso de carbono de la fotosíntesis se desvía hacia la vía de la producción de lípidos (Raja, Shanmugam, Ganesan, \& Carvalho, 2014).

Dentro de las varias alternativas tecnológicas, la producción de biocombustibles ha recibido mucho interés científico en las últimas décadas (Milledge, 2011; Quinn \& Davis, 2015). Los métodos actuales de cultivo de microalgas para producción de biocombustibles resultan costosos (Jonker \& Faaij, 2013; Fon Sing, Isdepsky, Borowitzka, \& Moheimani, 2013), por lo que una alternativa económica y ambientalmente viable seria aprovechar los efluentes de sistemas lagunares tales como lagunas de estabilización (WSP) y lagunas de algas de alta tasa (HRAP), que contienen altas concentraciones de estos microorganismos (Durazno, 2009), con una notable reducción de la huella de carbono global generada por el sistema de tratamiento. Aunque el uso solo de HRAP's para la producción de biocombustibles no es económico, el acoplamiento del tratamiento de las aguas residuales con la producción de biocombustibles se considera financieramente viable (Sutherland, Turnbull, Broady, \& Craggs, 2014; Sutherland, Howard-Williams, Turnbull, 
Broady, \& Craggs, 2014). Una gran ventaja de las HRAP's sobre las WSP's es la recuperación del recurso de la biomasa algal, para usarse como fertilizante, alimento rico en proteínas o biocombustible, y agua como efluente tratado a un estandar alto. Los principales tipos de algas presentes en WSP son las verdes (Chlorophyta) y las pigmentadas (Euglenophyta). Los géneros más importantes de estos grupos son Chlorella, Chlamydomonas y Euglena, de los cuales estos dos últimos poseen flagelos. Una tercera división de algas presentes en el sistema son las Cianobacterias, que poseen características de bacterias y algas pero que son clasificadas como bacterias. Estos organismos no tienen orgánulos locomotores, pero son capaces de moverse a través del sistema por deslizamiento. Las Cianobacterias típicamente proliferan en condiciones de $\mathrm{pH}$ bajo y baja disponibilidad de nutrientes, lo que es un ambiente desfavorable para el crecimiento de las Chlorophytas. Las Cianobacterias más importantes presentes en las WSP's son Oscillatoria, Phormidium, Anacystis y Anabaena. Otros tipos de algas que se pueden encontrar en las WSP's son Bacillariophyta y Chrysophyta (Sperling, 2007). Las especies de algas que comúnmente se encuentran en las plantas de tratamiento del tipo HRAP's (e.g. Scenedesmus sp, Micractiniumsp, Actinastrumsp, y Pediastrum sp) pueden crecer como colonias grandes sedimentables (diámetro de colonia de 50 a $200 \mu \mathrm{m}$ ), y también forman grandes bio-flóculos (diámetro $>500 \mu \mathrm{m}$ ), asociados con bacterias (Alvarado, Vedantam, Goethals, \& Nopens, 2012).

El objetivo de este estudio es realizar un análisis cuantitativo de la composición de lípidos de varias familias de microalgas para su potencial uso como biocombustibles con procedimientos gravimétricos. Además, determinar la eficiencia de extracción usando diferentes solventes para la extracción de lípidos a partir de biomasa algal con el método Soxhlet. Estudiar la productividad de lípidos con las microalgas Chlorella y Scenedesmus cultivadas bajo diferentes condiciones de nutrientes. Finamente, comparar la productividad de lípido aplicando un pretratamiento de disrupción celular térmico y físico a la biomasa de la microalga Chlorella con respecto a la biomasa sin pretratamiento. Este proyecto representa una fase inicial de investigación que permitirá establecer futuras líneas de investigación para aprovechar las nuevas fuentes de energía renovable como el biocombustible, producido mediante la extracción de lípidos de microalgas en las condiciones expuestas de la serranía ecuatoriana.

\section{MATERIALES Y MÉTODOS}

\subsection{Instrumentos}

Una centrífuga Thermo Scientific Heraeus Megafuge 8. Una bomba de succión, un filtro de porcelana, y un filtro de papel de Whatman de $110 \mathrm{~mm}$ de diámetro. Equipo Soxhlet P-Selecta Uniplac de placas circulares 6002316 para la extracción de lípidos. Para pesar se utilizó una Balanza de precisión de $0.0001 \mathrm{~g}$ "Excellence Analytical Balances" modelo XS-204 de METTLER TOLEDO. Todos los solventes utilizados eran de grado HPLC con pureza $>99.5 \%$.

\subsection{Cepas y medio de cultivo}

Se empleó biomasa algal de diferentes familias de microalgas provenientes del proyecto VLIR Plantas Medicinales de la Universidad de Cuenca, en donde se realizó un proceso de aislamiento de diferentes cepas de microalgas. Dos familias fueron identificadas: Chlorella y Scenedesmus, procedentes de las lagunas de maduración de la PTAR ubicada en el sector Ucubamba de la ciudad de Cuenca. Tres familias de microalgas provenientes de diferentes embalses no pudieron ser identificadas pero, de acuerdo al proyecto, fueron clasificadas como cianobacterias; para que estas pudieran ser aisladas, se asignó los siguientes nombres genéricos: $\mathrm{H} 1$, proveniente del Parque Nacional "El Cajas", y, FF.Especie 1 y FF.Especie 3, provenientes del sector La Josefina, en el río Paute, provincia del Azuay.

Se controló las condiciones de cultivo proporcionando luz artificial, con ciclos alternados de una hora luz y una hora obscuridad. Se controló que las algas no se sedimenten y adhieran a las paredes de los reactores mediante agitadores magnéticos a una velocidad de $150 \mathrm{rpm}$. Se adicionó oxígeno al reactor, con un compresor tipo pecera en el cual se conectó la manguera de diámetro 1/4", y, al final de esta, el difusor de aire. Se monitoreo la medida de $\mathrm{pH}$ utilizando un $\mathrm{pH}$ metro YSI MultiLab IDS 4010-2. Cuando los valores de $\mathrm{pH}$ sobrepasaban el rango óptimo, éste se controló mediante la adición de pulsos de $\mathrm{CO}_{2}$. Si el pH del cultivo estaba por debajo del rango óptimo, éste se reguló con la adición de bicarbonato. Se cultivaron en un medio comprendido por bicarbonato de Sodio $\mathrm{NaHCO}_{3}$ y abono completo que contiene: $12 \%$ de Nitrógeno, $12 \%$ Fósforo, $17 \%$ de Potasio, $2 \%$ de Magnesio y otros micronutrientes incluyendo pulsos de dióxido de carbono proporcionando una concentración de $0.1 \mathrm{~g} \mathrm{l}^{-1}$ de NPK y $0.07 \mathrm{~g}^{-1}$ de bicarbonato. Se experimentó una segunda etapa de cultivo durante tres semanas en la que se sometió a las familias Chlorella y Scenedesmus a condiciones de estrés con un suministro de nutrientes igual a la mitad de la concentración utilizada en condiciones ideales de crecimiento. Estas concentraciones de nutrientes fueron de $0.05 \mathrm{~g} \mathrm{l}^{-1}$ de NPK y $0.07 \mathrm{~g} \mathrm{l}^{-1}$ de bicarbonato. La biomasa húmeda se cosechó de los fotobioreactores, se centrifugó a una velocidad de rotación de 4000 rpm, se filtró y se secó al horno a una temperatura de $37^{\circ} \mathrm{C}$ durante aproximadamente $24 \mathrm{~h}$. Se obtuvieron escamas secas de biomasa y se pulverizó utilizando un mortero de porcelana.

Al final del proceso de extracción, que normalmente dura unas pocas horas, el balón de ebullición con el lípido extraído es removido, el disolvente evaporado y la masa remanente del lípido extraído es medida (Ramluckan, Moodley, \& Bux, 2014).

\subsection{Experimentación}

Todos los análisis se realizaron por duplicado con $1 \mathrm{~g}$ de muestra de biomasa microalgal seca y pulverizada, se pesó con precisión en un cartucho de extracción. El cartucho con la muestra fue transferida a la cámara de extracción en el aparato Soxhlet. El solvente fue colocado en la cámara de extracción teniendo en cuenta que su volumen sea capaz de alcanzar un sifonamiento en el extractor, se utilizó una cantidad de $150 \mathrm{ml}$ del solvente y se colocó en las placas de calefacción. Se abrió el suministro de agua de refrigeración a los condensadores para asegurar un continuo reciclaje del solvente. Según Ramluckan et al. (2014) se recomienda que la extracción se realice a la temperatura de ebullición de los solventes. Las temperaturas del punto de ebullición se programaron 
utilizando puntos de ebullición de los solventes mostrados en la Tabla 1. El equipo Soxhlet usado en este proyecto contiene un dial como indicador relativo de temperatura. En el manual se menciona que las placas circulares calefactoras están diseñadas para trabajar hasta una temperatura máxima de $400^{\circ} \mathrm{C}$. Debido a que no se conoce a que temperatura correspondía cada nivel del indicador, esta se determinó utilizando un termómetro infrarrojo. Por lo tanto, se colocó el indicador de temperatura en el nivel 7 para los casos en los que se utilizaron solventes con puntos de ebullición altos, como el etanol, y un nivel tres o cuatro cuando se utilizaron solventes con puntos de ebullición bajos como la acetona y éter dietílico (datos no mostrados). Las extracciones se llevaron a cabo en forma sucesiva por la recirculación del solvente, donde los lípidos extraídos permanecieron en el fondo del balón de ebullición. Se finalizó la extracción cuando el solvente recuperó su color inicial (transparente) dentro de la cámara de extracción, apreciándose en forma visual. Terminado el proceso de extracción de lípidos y recuperación de solvente, se extrajo el balón de ebullición de $500 \mathrm{ml}$ de capacidad con los lípidos extraídos; este balón fue pesado previo a la extracción (vacío). El solvente se eliminó por evaporación en una estufa durante una hora y a una temperatura de $110^{\circ} \mathrm{C}$. Los balones de ebullición se transfirieron a continuación a un desecador hasta que se enfríe durante aproximadamente 30 minutos $\mathrm{y}$, a continuación, se volvió a pesar en la balanza analítica para obtener el peso seco del balón de ebullición más contenido de lípido algal. Se utilizó el Hexano como blanco para establecer la línea base para el rango en el que se hicieron mediciones.

Seis solventes fueron utilizados para la extracción Tabla 1. Propiedades relevantes de los solventes usados (Ramluckan et al., 2014).(Tabla 1). La metodología de extracción utilizada consistió en solventes individuales y mezclas binarias de solventes, utilizando los mismos protocolos de extracción utilizados para la extracción con solventes individuales. Las diferentes extracciones para las familias Chlorella y Scenedesmus en cuanto al uso de solventes individuales se realizaron usando solo cloroformo, etanol, n-hexano y éter dietílico. En cuanto a las combinaciones binarias realizadas fueron, cloroformo:metanol (1:2), metanol:n- hexano (1:3), cloroformo:etanol (1:3), etanol:hexano (1:3), cloroformo:etanol (1:1), éter dietílico:etanol (1:1), cloroformo:hexano (1:2) y, por último, hexano:acetona (1:1). Para efectos de optimizar los procesos experimentales y los recursos, se realizó la extracción utilizando los solventes mencionados en una primera etapa, pero únicamente con las especies Chlorella y Scenedesmus. El análisis de los resultados, en esta primera etapa, sirvió para seleccionar las 4 diferentes combinaciones de solventes que dieron los mejores resultados (mayores concentraciones lipídicas) en las especies estudiadas. Para las especies, F.F. Especie 1, F.F. Especie 3 y $\mathrm{H} 1$ se realizaron las extracciones con las combinaciones de solventes seleccionadas con los mejores resultados en la etapa previa.

La segunda etapa de cultivo duró tres semanas. Durante este tiempo se sometió a las familias Chlorella y Scenedesmus a condiciones de estrés, provocado por la disminución de nutrientes en el cultivo, específicamente a través de un suministro de nutrientes igual a la mitad de la concentración utilizada en condiciones ideales de crecimiento, esto, con el fin de incrementar la productividad lipídica usando la combinación binaria de solventes cloroformo: metanol (1:2) y utilizando el mismo protocolo de extracción.

Tabla 1. Propiedades relevantes de los solventes usados (Ramluckan et al., 2014).

\begin{tabular}{lccc}
\hline Solvente & $\begin{array}{c}\text { Índice de } \\
\text { polaridad }\end{array}$ & $\begin{array}{c}\text { Punto de } \\
\text { ebullición } \\
\left({ }^{\circ} \mathrm{C}\right)\end{array}$ & $\begin{array}{c}\text { Densidad } \\
\text { a } 25^{\circ} \mathrm{C} \\
\left(\mathrm{g} \mathrm{mL}^{-1}\right)\end{array}$ \\
\hline Hexano & 0.1 & 69.0 & 0.659 \\
Éter Dietílico & 2.8 & 34.6 & 0.706 \\
Cloroformo & 4.1 & $60.5-61.5$ & 1.492 \\
Acetona & 5.1 & 56.0 & 0.791 \\
Metanol & 5.1 & 64.7 & 0.792 \\
Etanol & 5.2 & 78.0 & 0.789 \\
\hline $\begin{array}{l}\text { Agua (solo } \\
\text { para } \\
\text { comparación) }\end{array}$ & 10.2 & 100.0 & 1.000 \\
\hline
\end{tabular}

Se realizaron pretratamientos de biomasa algal con muestras de la familia Chlorella con el fin de obtener una mayor productividad de lípido más clorofila. En la Tabla 2 se observan los resultados de pretratar la biomasa algal en el autoclave y en el liofilizador. El proceso de liofilización duró alrededor de 24 horas. Para este procedimiento se usó un Liofilizador LABCONCO FreeZone de 2.5 litros con una plataforma de 12 puertos. Para el autoclavado se sometió a la biomasa algal seca sin triturar durante $30 \mathrm{~min}$, a una presión de $100 \mathrm{MPa}$ y a $100^{\circ} \mathrm{C}$, en un autoclave marca Trident modelo EA-632, colocándose previamente la muestra en una caja Petri (envuelta en papel aluminio y papel vegetal). Para la extracción se utilizó la combinación binaria de solventes cloroformo: metanol (1:2) utilizando el mismo protocolo de extracción.

\subsection{Cálculo de las cantidades de lípido y clorofila}

La masa total de lípidos extraído $\left(\mathrm{P}_{1}\right)$ se determinó a partir de la diferencia de la masa del balón de ebullición antes y después de la extracción. El valor se expresó como un porcentaje de la masa original de biomasa pesada $\left(\mathrm{P}_{\mathrm{v}}\right)$. La cantidad de extracto de lípidos extraídos en la muestra se calculó utilizando la siguiente fórmula general:

$\%$ de lípido extraído + clorofila $=$

$$
\frac{P_{l}-P_{v}}{\text { peso de muestra algal seca }} * 100
$$

dónde:

$P_{l}$ : Peso del balón de ebullición más lípido algal y clorofila.

$P_{v}$ : Peso del balón de ebullición vacío

\section{RESULTADOS Y DISCUSIÓN}

\subsection{Porcentajes de lípido extraído de diferentes familias}

Para la familia Chorella, los resultados (Fig. 2) muestran el promedio de los análisis duplicados realizados con cada solvente y combinación binaria de éstos, también se incluye el error relativo. Los valores más altos $(>16 \%)$ de 
lípido extraído fueron alcanzados con la mezcla binaria cloroformo:metanol (1:2), metanol:hexano (1:3), etanol y cloroformo:etanol (1:3), con un tiempo de extracción promedio de $4 \mathrm{~h} 30 \mathrm{~min}$. Los solventes restantes arrojaron porcentajes de lípidos extraídos entre 5 y $15 \%$.

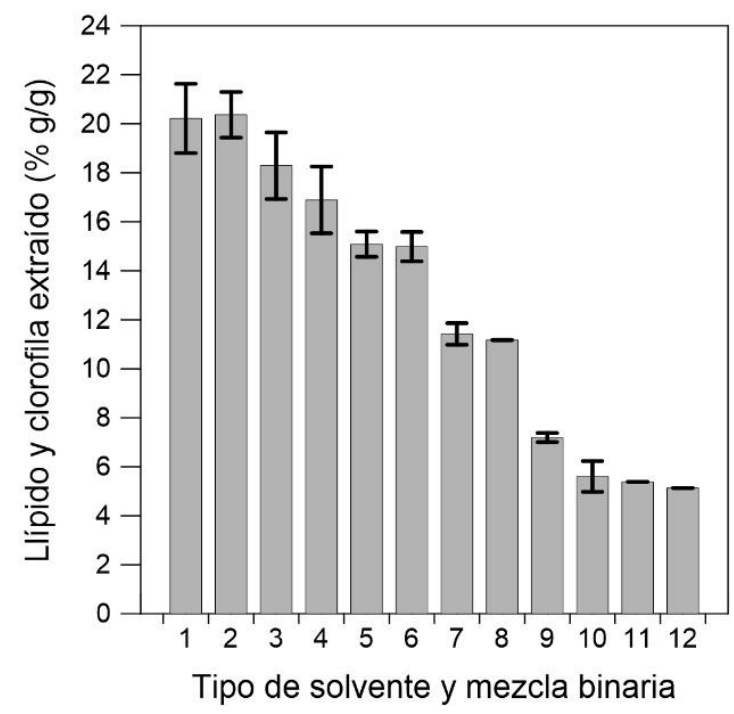

Figura 2. Porcentaje de lípido y clorofila extraído por el método Soxhlet utilizando, solventes individuales y

mezclas binarias para la familia Chlorella $[1=$

Cloroformo: Metanol (1:2); 2 = Metanol:Hexano (1:3); 3

$=$ Etanol; 4 = Cloroformo:Etanol (1:3); 5 =

Etanol:Hexano (1:3); 6 = Cloroformo:Etanol $(1: 1) ; 7=$

Cloroformo; 8 = Éter Dietílico:Etanol (1:1); $9=$

Cloroformo:Hexano (1:2); $10=$ Hexano; 11 = Eter

Dietilico; 12 = Hexano:Acetona (1:1)].

Basado en el principio de extracción, donde lo "semejante disuelve lo semejante", el alto porcentaje de lípido obtenido con la mezcla cloroformo:etanol (1:3) indicó que la especie Chlorella contiene cantidades de lípidos polares y neutros. Cuando en las extracciones se utilizó un solvente con etanol, el porcentaje fue superior al $18 \%$, mientras que con cloroformo, este porcentaje fue mayor al $11 \%$. Cuando se compararon estos con el valor obtenido usando la mezcla binaria cloroformo:etanol (1:3) el porcentaje de lípidos fue mayor al $14 \%$ lo cual indica que la combinación de solventes mejora la eficiencia de un solvente individual que, generalmente, extrae un porcentaje de lípidos menor. La mejor eficiencia de extracción fue producida por la mezcla metanol:hexano (1:3), con un porcentaje de lípidos de $20.37 \%$, presentando una mínima diferencia con la mezcla cloroformo:metanol (1:2), con un porcentaje del $20.22 \%$.

El porcentaje de lípido extraído con éter dietílico fue de $5.38 \%$, al ser este un solvente no polar los lípidos obtenidos en su mayoría no fueron apolares. Cabe mencionar que, al utilizar este solvente, se tuvieron ciertos inconvenientes debido a su alta volatilidad ya que, durante la extracción, se evaporó gran cantidad de éste. Esto impidió el sifonamiento del mismo en la cámara de extracción por lo que se tuvo que continuamente agregar una cantidad adicional de solvente en la cámara de extracción. Su olor característico y toxicidad impidió que éste se pueda usar para la familia Scenedesmus.
Para la familia Scenedesmus, los resultados de porcentajes de lípidos más clorofila y su valor relativo se ilustran en la Figura 3. Los valores más altos (>17\%) de lípido extraído fueron alcanzados con las mezclas binarias cloroformo:metanol (1:2), metanol:hexano (1:3), etanol y cloroformo:etanol (1:3), con un tiempo de extracción promedio de $4 \mathrm{~h} 50 \mathrm{~min}$. Los porcentajes de lípidos obtenidos con las mezclas metanol:hexano (1:3), etanol y cloroformo:etanol (1:3) no evidenciaron una gran variabilidad en sus valores, los cuales fueron de $17.95 \%$, 16.86 y $17.59 \%$, respectivamente. El porcentaje más bajo de extracción fue con el solvente n-hexano, con un valor de $7.04 \%$.

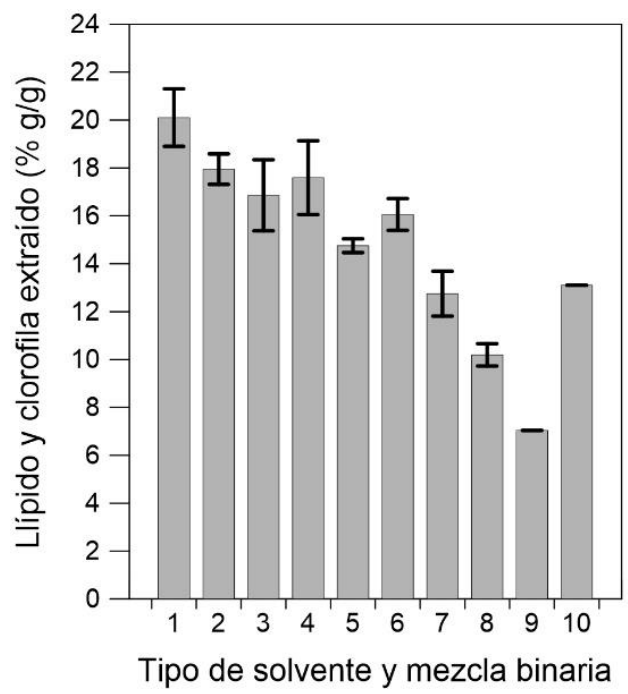

Figura 3. Porcentaje de lípido y clorofila extraído por el método Soxhlet utilizando, solventes individuales y mezclas binarias para la familia Scenedesmus $[1=$ Cloroform:Metanol (1,2); 2 = Metanol:Hexano (1:3); 3 = Etanol; 4 = Cloroformo:Etanol (1:3); 5 = Etanol:Hexano (1:3); 6 = Cloroformo:Etanol (1:1); 7 = Cloroformo; $8=$ Cloroformo:hexano (1:2); $9=$ Hexano; $10=$ Hexano:Acetona (1:1)].

Para la familia F.F. Especie 3 se evidenció que el valor más alto de porcentaje de lípido extraído más clorofila fue con la mezcla metanol:hexano (1:3) de $19.17 \%$, seguido por un $18.31 \%$ de la mezcla cloroformo:metanol (1:2). Con el solvente etanol se obtuvo $13.53 \%$ de lípido más clorofila y con la mezcla cloroformo:etanol (1:3) un valor de $12.69 \%$ (Fig. 4). Las dos primeras mezclas no presentaron una mayor variación en el porcentaje de lípidos más clorofila extraída, por lo que, para esta especie, cualquiera de estas pude ser elegida como la más eficiente en la extracción de lípidos.

Para la familia F.F. Especie 1, el valor más alto de porcentaje de lípido más clorofila extraído fue con la mezcla cloroformo:metanol (1:2) de $17.69 \%$; mientras que con la mezcla metanol:hexano (1:3) el valor fue de $13.96 \%$. La extracción realizada con etanol resultó en un 9.23\% de lípido más clorofila. La mezcla cloroformo:etanol (1:3) dio el valor más bajo, resultando de $5.77 \%$ (Fig. 5). 


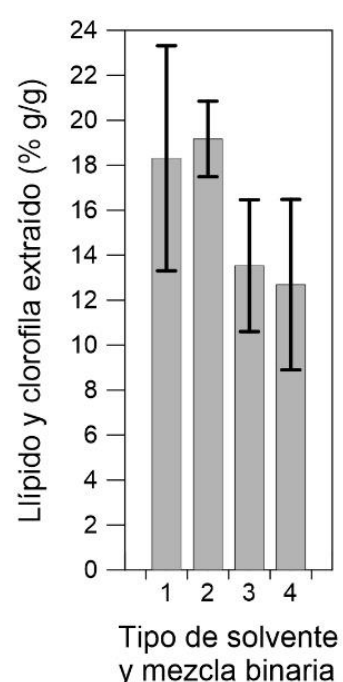

Figura 4. Porcentaje de lípido y clorofila extraído por el método Soxhlet utilizando, solventes individuales y mezclas binarias para la familia F.F. Especie 3.

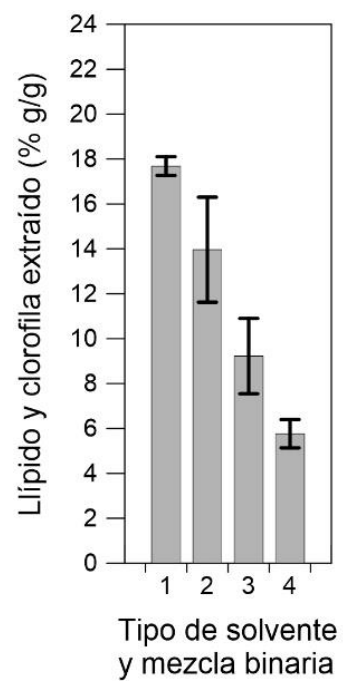

Figura 5. Porcentaje de lípido y clorofila extraído por el método Soxhlet utilizando, solventes individuales y mezclas binarias para la familia F.F. Especie 1.
[1 = Cloroformo: Metanol (1:2); 2 = Metanol:Hexano (1:3); 3 = Etanol; 4 = Cloroformo:Etanol (1:3)]

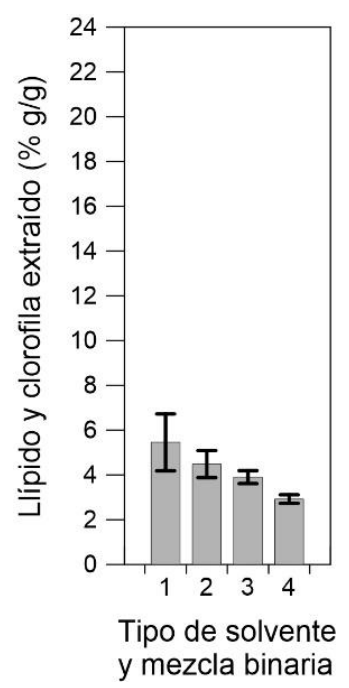

Figura 6. Porcentaje de lípido y clorofila extraído por el método Soxhlet utilizando, solventes individuales y mezclas binarias para la familia H1 [1 = Cloroformo: Metanol (1:2); 2 = Metanol:Hexano (1:3); 3 = Etanol; 4 = Cloroformo:Etanol (1:3)].

Para la familia H1, el valor más alto de porcentaje de lípido extraído más clorofila fue con la mezcla cloroformo:metanol (1:2) de 5.46\%, mientras que con la mezcla metanol:hexano (1:3) fue de $4.49 \%$. La extracción realizada con etanol fue de $3.91 \%$ de lípido más clorofila. La mezcla cloroformo:etanol (1:3) dio el valor más bajo $2.92 \%$ (Fig. 6). Se puede observar que, para esta especie, todos los valores de porcentaje de lípido más clorofila fueron relativamente bajos.

\subsection{Productividad de lípidos bajo diferentes condiciones de nutrientes}

Para las familias de Chlorella y Scenedesmus, la Tabla 2 muestra los resultados de la extracción de lípido más clorofila, en las dos etapas de cultivo.

Tabla 2. Porcentaje de lípido más clorofila en la primera y segunda etapa de cultivo con diferentes condiciones de cultivo para las familias Chlorella y Scenedesmus.

\begin{tabular}{lcc}
\hline & \multicolumn{2}{c}{ Familias de microalgas } \\
\hline $\begin{array}{l}\text { Etapas de } \\
\text { cultivo }\end{array}$ & $\begin{array}{l}\text { Chlorella [Lípido } \\
+ \text { clorofila }(\%)]\end{array}$ & $\begin{array}{l}\text { Scenedesmus } \\
\text { [Lípido + clorofila } \\
(\%)]\end{array}$ \\
\hline 1ra etapa & 20.22 & 20.10 \\
2da etapa & 22.46 & 23.17 \\
\hline
\end{tabular}

1ra etapa: $0.07 \mathrm{~g} \mathrm{l}^{-1}$ de bicarbonato; $0.1 \mathrm{~g} \mathrm{l}^{-1}$ de nutrientes 2da etapa: $0.07 \mathrm{~g} \mathrm{l}^{-1}$ de bicarbonato; $0.05 \mathrm{~g} \mathrm{l}^{-1}$ de nutrientes Combinación de solventes usada para la extracción de lipido: cloroformo:metanol (1:2)

Se puede observar que los porcentajes en la segunda etapa de cultivo (condiciones de estrés) son mayores. Sin embargo, la diferencia respecto a las condiciones con un suministro normal de nutrientes no es significativa. Sería necesario realizar nuevas experimentaciones sometiendo a los cultivos a concentraciones de nutrientes mucho menores para lograr que la productividad de lípidos aumente significativamente.

\subsection{Porcentaje de lípidos bajo condiciones de pretratamiento}

En la Tabla 3 se observan los resultados de pretratar la biomasa algal en el autoclave y en el liofilizador.

Tabla 3. Porcentajes de lípido más clorofila, obtenido con pretratamientos de disrupción celular térmico y mecánico.

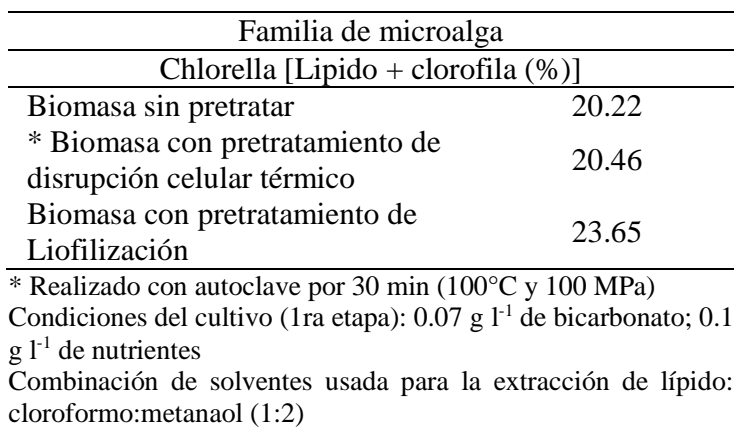

Se puede observar que el porcentaje de aumento de productividad cuando se sometió al autoclave fue prácticamente nulo debido a que sólo aumentó $0.24 \%$. En fuentes bibliográficas revisadas se menciona que la biomasa algal debe permanecer en el autoclave en un tiempo óptimo de 1 a 3 horas. Por la gran energía requerida para el encendido del autoclave del laboratorio de Sanitaria de la Facultad de Ingeniería, la biomasa algal fue sometida al autoclave durante únicamente 30 minutos, resultando en un mínimo aumento del porcentaje mostrado.

En cuanto a la liofilización, los resultados muestran un aumento del $3.43 \%$, consideramos que este aumento no es eficiente, debido a las grandes cantidades de energía que 
son requeridas para este proceso, representando un gasto energético innecesario.

A futuro, es necesario analizar, en forma cuantitativa, la energía empleada en cada una de estas técnicas de disrupción celular. Esto, con el propósito de realizar una comparación del balance energético total de la producción de lípidos bajo las condiciones experimentadas en la presente investigación.

\section{CONCLUSIÓN}

El rendimiento más alto de lípidos para las 5 familias de microalgas estudiadas fueron los siguientes: Chlorella obtuvo $20.37 \%$ y F.F. Especie 3 obtuvo $19.17 \%$ con la mezcla metanol:hexano (1:3), Scenedesmus obtuvo $20.10 \%$, F.F. Especie 1 obtuvo $17.69 \%$ y $H 1$ obtuvo $5.46 \%$, con la mezcla cloroformo:metanol (1:2), de lípido más clorofila. Por esta razón se recomiendan estas dos mezclas como las más eficientes para la extracción de lípidos más clorofila.

Con los resultados obtenidos se puede concluir que la combinación de solventes mejora la eficiencia del solvente que individualmente extrae un porcentaje menor de lípidos. Combinaciones mayores no se recomiendan debido a que son poco prácticas e incrementarían el costo de la producción del biodiesel principalmente a grandes escalas. La familia Chlorella es la que mayor productividad de lípidos posee a diferencia de la familia $H 1$ que produce un promedio de $4.19 \%$ de lípidos más clorofila para todas las combinaciones de solventes que se realizaron.

Basado en el principio de extracción donde lo "semejante disuelve lo semejante" el alto porcentaje de lípido obtenido con la mezcla cloroformo:etanol (1:3) indicó que las familias Chlorella y Scenedesmus contienen cantidades de lípidos polares y neutros. El porcentaje de lípido extraído con éter dietílico fue de $5.38 \%$ en la familia Chlorella, al ser éste un solvente no polar los lípidos obtenidos en su mayoría no fueron apolares.

\section{AGRADECIMIENTOS}

Los autores expresan su agradecimiento a la Dirección de Investigación de la Universidad de Cuenca por el financiamiento para la ejecución de la presente investigación.

\section{REFERENCIAS}

Abou-Shanab, R. A. I., Hwang, J. H., Cho, Y., Min, B., \& Jeon, B. H. (2011). Characterization of microalgal species isolated from fresh water bodies as a potential source for biodiesel production. Applied Energy, 88(10), 3300-3306.

Alvarado, A., Vedantam, S., Goethals, P., \& Nopens, I. (2012). A compartmental model to describe hydraulics in a full-scale waste stabilization pond. Water Research, 46(2), 521-530.
Amaro, H. M., Guedes, A. C., \& Malcata, F. X. (2011) Advances and perspectives in using microalgae to produce biodiesel. Applied Energy, 88(10), 3402-3410.

Araujo, G. S., Matos, L. J., Fernandes, J. O., Cartaxo, S. J., Goncalves, L. R., Fernandes, F. A., \& Farias, W. R. (2013). Extraction of lipids from microalgae by ultrasound application: prospection of the optimal extraction method. Ultrasonics Sonochemistry, 20(1), 95-98.

Arias Peñaranda, M. T., Martínez Roldán, A. D. J., \& Cañizares Villanueva, R. O. (2013). Producción de biodiesel a partir de microalgas: Parámetros de cultivo que afectan la producción de lípidos. Acta Biológica Colombiana, 18(1). Disponible en http://www.redalyc.org/resumen.oa?id=319028010004

Brennan, L., \& Owende, P. (2010). Biofuels from microalgae - A review of technologies for production, processing, and extractions of biofuels and coproducts. Renewable and Sustainable Energy Reviews, 14(2), 557-577.

https://doi.org/10.1016/j.rser.2009.10.009

Cai, T., Park, S. Y., \& Li, Y. (2013). Nutrient recovery from wastewater streams by microalgae: Status and prospects. Renewable and Sustainable Energy Reviews, 19, 360-369. https://doi.org/10.1016/j.rser.2012.11.030

Chen, G., Zhao, L., \& Qi, Y. (2015). Enhancing the productivity of microalgae cultivated in wastewater toward biofuel production: A critical review. Applied Energy, 137, 282-291. https://doi.org/10.1016/j.apenergy.2014.10.032

Dragone, G. D., Fernandes, B. F., Vicente, A., \& Teixeira, J. A. (2010). Current research, technology and education topics. In: Sánchez, M. D. P., Serrano, L., \& Martínez, A. (2009). Biodiesel a partir de microalgas. BioTecnología, 13(3), 38-61.

González, A., Viatcheslav, K., \& Guzmán, A. (2009). Desarrollo de métodos de extracción de aceite en la cadena de producción de biodiesel a partir de microalgas. Prospectuve, 7(2), 53-60.

Garibay, A., Vázquez-Duhalt, R., Sánchez, M.d.P., Serrano, L. and Martínez, A. (2009) Biodiesel a partir de microalgas. BioTecnología, 13(3), 38-61.

Grobbelaar, J. U. (2004). Handbook of Microalgal Culture: Biotechnology and Applied Phycology. Richmond, A. (Ed), pp. 97-115. Oxford, UK: Blackwell Publishing Ltd.

Halim, R., Danquah, M. K., \& Webley, P. A. (2012). Extraction of oil from microalgae for biodiesel production: A review. Biotechnology Advances, 30(3), 709-732.

Jonker, J. G. G., \& Faaij, A. P. C. (2013). Technoeconomic assessment of micro-algae as feedstock for renewable bio-energy production. Applied Energy, 102, 461-475.

Khan, M. I., Shin, J. H., \& Kim, J. D. (2018). The promising future of microalgae: current status, challenges, and optimization of a sustainable and renewable industry for biofuels, feed, and other products. Microbial Cell Factories, 17(36), 1-21. https://doi.org/10.1186/s12934-018-0879-x 
Lee, A. K., Lewis, D. M., \& Ashman, P. J. (2012). Disruption of microalgal cells for the extraction of lipids for biofuels: Processes and specific energy requirements. Biomass and Bioenergy, 46, 89-101. https://doi.org/10.1016/j.biombioe.2012.06.034

Medipally, S. R., Yusoff, F. M., Banerjee, S., \& Shariff, M. (2015). Microalgae as sustainable renewable energy feedstock for biofuel production. BioMed Research International, 2015, 13 pp. https://doi.org/10.1155/2015/519513

Milano, J., Ong, H. C., Masjuki, H. H., Chong, W. T., Lam, M. K., Loh, P. K., \& Vellayan, V. (2016). Microalgae biofuels as an alternative to fossil fuel for power generation. Renewable and Sustainable Energy Reviews, 58, 180-197. https://doi.org/10.1016/j.rser.2015.12.150

Milledge, J. J. (2011). Commercial application of microalgae other than as biofuels: a brief review. Reviews in Environmental Science and Bio/Technology, 10(1), 31-41. https://doi.org/10.1007/s11157-010-9214-7

Quinn, J. C., \& Davis, R. (2015). The potentials and challenges of algae-based biofuels: A review of the techno-economic, life cycle, and resource assessment modeling. Bioresource Technology, 184, 444-452. https://doi.org/10.1016/j.biortech.2014.10.075
Raja, R., Shanmugam, H., Ganesan, V., \& Carvalho, I. S. (2014). Biomass from Microalgae: An Overview. Journal of Oceanography and Marine Research, 2(1), 1-7. https://doi.org/10.4172/2332-2632.1000118

Ramluckan, K., Moodley, K.G., \& Bux, F. (2014). An evaluation of the efficacy of using selected solvents for the extraction of lipids from algal biomass by the soxhlet extraction method. Fuel, 116, 103-108.

Sathish, A., \& Sims, R. C. (2012). Biodiesel production from mixed culture algae via a wet lipid extraction procedure. Bioreource Technology, 118, 643-647. https://doi.org/10.1016/j.biortech.2012.05.118

Sutherland, D. L., Turnbull, M. H., Broady, P. A., \& Craggs R. J. (2014). Effects of two different nutrient loads on microalgal production, nutrient removal and photosynthetic efficiency in pilot-scale wastewater high rate algal ponds. Water Research, 1(11), 53-62.

Sutherland, D. L., Howard-Williams, C., Turnbull, M. H., Broady, P. A., \& Craggs, R. J. (2014). Enhancing microalgal photosynthesis and productivity in wastewater treatment high rate algal ponds for biofuel production. Bioresource Technology, 184, 222-229.

Taher, H., Al-Zuhair, S., Al-Marzouqi, A. H., Haik, Y., \& Farid, M. (2014). Effective extraction of microalgae lipids from wet biomass for biodiesel production. Biomass and Bioenergy, 66(0), 159-167. 